DOI: https://doi.org/10.24867/01FA07Popadic

\title{
REHABILITACIONI CENTAR- NOVI MODEL CENTRA ZA ODVIKAVANJE OD DROGE
}

\section{REHABILITATION CENTER- A NEW MODEL OF DRUG CENTER}

\author{
Ksenija Popadić, Milena Krklješ, Fakultet tehničkih nauka, Novi Sad
}

\begin{abstract}
Oblast - ARHITEKTURA
Kratak sadržaj - Ovaj rad ima pre svega za cilj predlog rešenja za doprinos u borbi protiv narkomanije, skretanje pažnje kako stručne, tako i šire javnosti na sveprisutnost ovog problema, $i$ na konstantan rast broja žrtava. Novi model centra za odvikavanje od droge, ima za cilj iznalaženje i prezentaciju upravo jednog novog pristupa aktuelnom problemu.
\end{abstract}

Ključne reči: Rehabilitacioni centar, terapijska zajednica, lečenje bolesti zavisnosti

\begin{abstract}
This research work primarily aims at contributing to the fight against drug addiction, drawing the attention of the expert and the wider public to the omnipresense of this problem, and the constant increase in the number of victims. The new model of center for drug rehab aims at funding and presenting just one new approach to the curent problem.
\end{abstract}

Keywords: Rehabilitation center, therapeutic community, treatment of addiction diseases

\section{UVOD}

Narkomanija je bolest sveopšte prisutna, i sve je veći broj ljudi koji se suočavaju sa ovim problemom. Od početka, do kraja poslednje decenije dvadesetog veka, broj narkomana u Srbiji je utrostručen [3]. Kada se bolesnik odluči na rehabilitaciju, pojavljuje se još jedan problem, a to je mesto lečenja, jer na Balkanu retko koji centar za odvikavanje od bolesti zavisnosti ima dobru koncepciju lečenja, te shodno tome, veliki broj pacijenata nakon nekog vremena odustane. Shodno tome, ovaj rad, baviće se projektovanjem jednog takvog ,procesa“, tj. rehabilitacionog centra.

Ovaj rad ima pre svega za cilj doprinos u borbi protiv narkomanije, skretanje pažnje kako stručne, tako i šire javnosti na sveprisutnost ovog problema, i na konstantan rast broja žrtava.

Osim toga, cilj rada, a ujedno i koncept, zasnovan je na samom toku i fazama lečenja, gde je krajnji ishod fizički i psihički oporavljena osoba, koja je spremna za povratak u „stvarnost“ i u društvo koje na nju neće gledati kao na „nesrećan slučaj“, već kao na zdravu jedinku, koja je sposobna da normalno radi i funkcioniše.

\section{NAPOMENA:}

Ovaj rad proistekao je iz master rada čiji mentor je bila dr Milena Krklješ, vanredni profesor.
Danas je na crnom tržištu širok spektar opijata i narkotika do kojih se dolazi relativno lako, i koji izazivaju veću, ili manju zavisnost. Kako se nalazi na međunarodnom putu droge koja spaja istok i zapada (tzv. Balkanska ruta), droga prolazi, ali se u velikoj meri i zadržava u našoj zemlji. Trenutno su najaktueniji sledeći narkotici: marihuana, LSD, kokain i krek, ekstazi, amfetamin i metamfetamin, metadon, heroin. Načini konzumacije su veoma različiti, a i oblici zavisnosti.

Pojam rehabilitacije koristi se kako u svakodnevnom govoru, tako kao i oblik stručne terminologije, a najčešće je povezan sa oblašću medicine. $U$ zavisnosti od tipologije $i$ primenjenog oblika lečenja, različita je i struktura i organizacija rehabilitacionih centara. Oni na prvom mestu treba da u potpunosti odgovaraju potrebama svojih pacijenata, i da omogće pravilan tok lečenja i komunikaciju pacijenata i osoblja.

\section{TERAPIJSKA ZAJEDNICA}

Terapijska zajednica je savremeni oblik institucionalnebolničke terapije koji ističe važnost interpersonalnih odnosa između pacijenata i personala, između personala međusobno, kao i pacijenata međusobno [6]. Može se koristiti u najrazličitijim sredinama, dnevnim centrima i bolnicama, ali i čitavim kompleksima koji predviđaju rad sa pacijentima na duži vremenski rok. Koncept ovog vida terapije počiva na ideji da milje čine osoblje i pacijenti, a kvalitet njihovih odnosa je direktno proporcionalan uspehu terapije.

\subsection{Razvoj terapijske zajednice kroz vreme}

Jedna od najšire prihvaćenih definicija terapijske zajednice zavisnika od narkomanije je Otenbergova teza iz 1993. godine o okruženju u kojem ,ljudi žive zajedno na organizovan i struktuiran način u cilju promovisanja promene i mogućnosti života bez droge u spoljašnjem društvu... Zajednica formira minijaturno društvo u kome stanovnici ispunjavaju karakteristične uloge, dizajnirana tako da promoviše prelazni proces“" [1].

\subsection{Faze lečenja}

Kada se zavisnik od narkotika prijavi u centar za rehabilitaciju, to pre svega znači da je postao svestan svog problema, ali ne mora biti svestan ozbiljnosti situacije $u$ kojoj je. Okvirni vremenski rok koji se uzima kao polazna pretpostavka za period izlečenja je dve godine. Pacijent tokom lečenja prolazi kroz četiri faze, kako je već pomenuto, odnosno faze A, D, C i B. 


\section{LOKACIJA}

Pri projektovanju objekata ovakve tipologije, za uspešnost celog procesa i funkcionisanja sistema, veoma bitnu, ako ne i presudnu ulogu ima odabir lokacije na kojoj će se graditi.
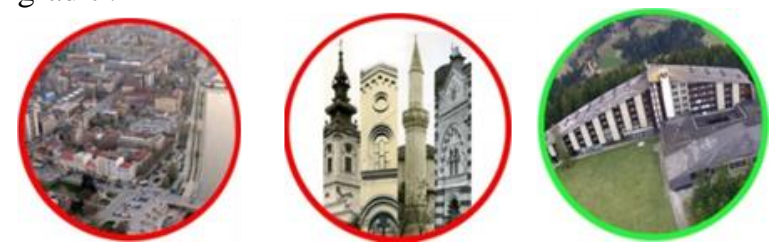

Slike 1-3. Tipovi klinika za terapijsku zajednicu

Rehabilitacioni centri koji su locirani u gradskom jezgru (slika 1), pokazali su se kao loša solucija iz razloga lečenja medikamentima. Tu se pacijenti veštačkom metodom leče od fizičke zavisnosti i ne bore se sami sa sobom, što je neophodno da shvate i prevaziđu razlog zbog kog su postali zavisni i probleme koje su time uzrokovali.

Još jedan od razloga koji rehabilitacione centre na ovakvim lokacijama čini lošim jeste laka dostupnost narkotika. Druga i dugo primenjivana metoda koja je na pojedinim mestima i dalje aktuelna, je lečenje zavisnika u verskim objektima (slika 2). Suština problema sa centrima na ovakvim lokacijama je u tome što ih na prvom mestu leče nestručna lica. Lečenje u ruralnim sredinama u vidu seoskog gazdinstva dalo je najbolje rezultate (slika 3).

\section{STUDIJA SLUČAJA}

Tema rehabilitacionih centara, veoma je opširna, a tipologija takvih objekata i kompleksa, veoma složena i kompleksna, pa joj se treba pristupiti obazrivo, i sa jednim jedinim ciljem, a to je put ka izlečenju ma kakve bolesti i potpuna podređenost potrebama lečenih. Savremen način projektovanja svakako podrazumeva promišljen i naučno zasnovan tretman u planiranju i dizajnu svih tipova objekata za rehabilitaciju.

Svaki pojedinačni slučaj ima svoje određene posebnosti i dobre i loše karakteristike. Prilikom izbora relevantnih primera, bilo je bitno da oni zadovolje nekoliko kriterijuma.

\subsubsection{Rehabilitacioni centar „Groot Klimmnedaal“"}

Arhitekta Koen van Velsen, u ovom projektu kao svoju polaznu ideju, zastupao je stav da će pozitivno, stumulativno okruženje, sa pristupom prirodi, pomoći rehabilitaciji pacijenata. Naime, pozicioniranje zgrade u šumu nije slučajnost- reč je o istraženom fenomenu prema kojem se bolesnici mnogo brže oporavljaju posmatrajući zelenilo šume.

Dakle, stabla umesto morfijuma. Kuća u prostoru deluje pre svega neupadljivo, poput ekstenzije šume, iako je reč o hiljadama kvadratnih metara prostora koji se proteže na 3 sprata (slika 4). Cela filozofija ovog centra zasnovana je na samopouzdanju i samokontroli pacijenata.

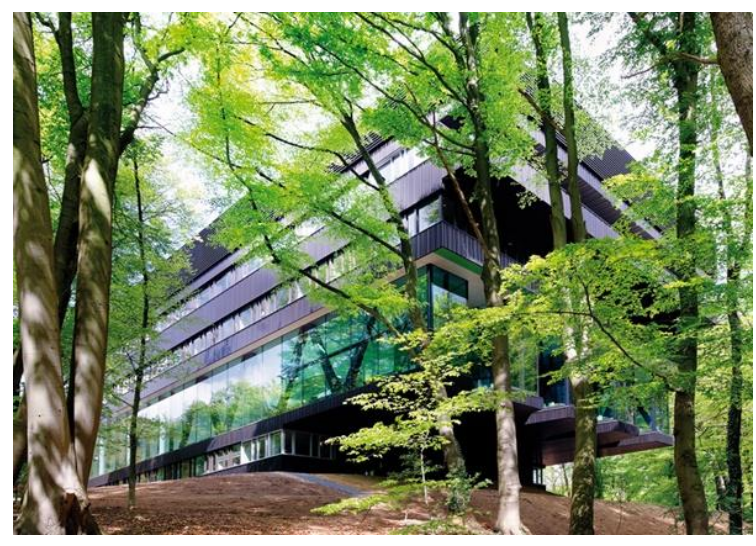

Slika 4. Rehabilitacioni centar ,,Groot Klimendaal“

Sama zgrada je rezultat intenzivne kolaboracije između arhitekata i korisnika, te njihovih prohteva. Na primer, sve stepenice, unutar centra su otvorene za korisnike, što je karakteristično za novi, holistički pristup projektovanja kuće. Dinamika i toplina enterijera postignute su obojenim zidovima, u primarnim, ali prigušenim tonovima.

\subsubsection{Centar „Sister Margareth Smith“}

„Sister Margareth Smith“ centar obezbeđuje stambene i ne-stambene usluge za lečenje bolesti zavisnosti, uključujući zavisnost od droge i alkohola, kockanja i poremečaja u ishrani. Centar je dizajniran tako da podrži sledeće vrednosti: saosećajnost i holističku brigu, dostojanstvo i poštovanje, veru, brižnot, inkluzivnost, istinoljubivost i poverenje. Zgrada je orijentisana na dva pejzaža, odnosno dva velika atrijumska vrta, jedan za stalne članove, drugi za posetioce. Oba dela obezbeđuju sigurno okruženje kako bi korisnici imali svoj mir i bili izolovani od spoljašnjih uticaja. Kompleks obuhvata kancelarije, učionice, istraživačke ustanove, stambene prostorije i vrske prostorije za klijente. U oblikovanju eksterijera, ali i enterijera kompleksa, korišćeni su prirodni materijali, u prvom redu drvo i tople boje koje daju osećaj topline i sigurnosti i stvaraju domaćinsku porodičnu atmosferu koja je pacijentima neophodna. Posebna pažnja je posvećena sportskim i rekreativnim aktivnostima, koje takođe daju veliki doprinos u kolektvnom lečenju.

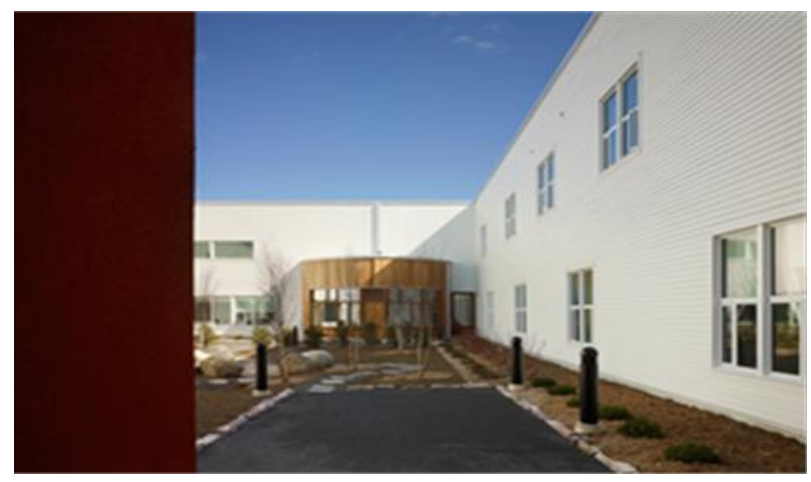

Slika 5. Rehabilitacioni centar ,, Sister Margareth Smith“ 


\subsection{3. „, Recovery Village“, Palmar lake, Colorado}

Ušuškana između crvenih stena Kolorada i mirne jezerske vode, ova klinika se kao i prethodne, dve bavi lečenjem zavisnosti od droge, alkohola, poremećaja u ishrani i drugih pitanja mentalnog zdravlja, daleko od pritiska svakodnevnog života, problema i nesreća. Rehabilitacioni centar je pozicioniran uz samu obalu jezera, okrenut prirodi, planinama i borovim šumama Kolorada. Kako sami osnivači naglašavaju, ovde se možete osetiti izolovano, ali ne i usamljeno. Centar je orijentisan ka osnaživanju duha i tela, vraćanju samopouzdanja i sistema vrednosti, a priroda služi kao inspiracija za obnovu života vrednog života.

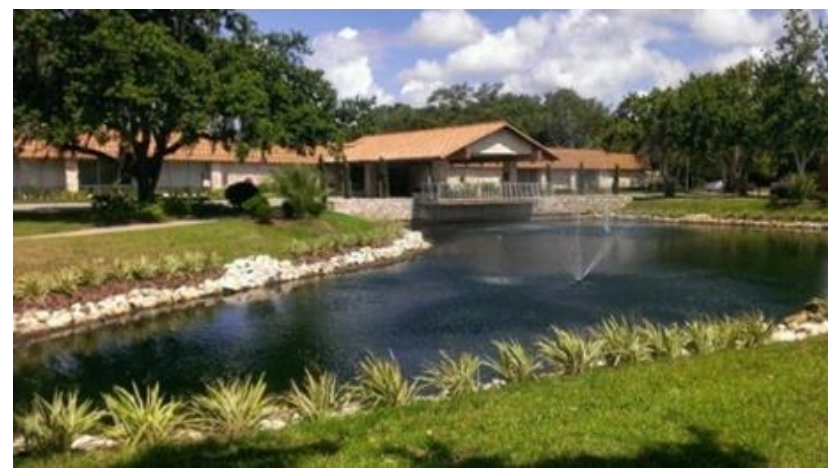

Slika 6. Recovery Village

\subsection{4. "Tranziciona soba", Holandija}

Istraživanjem je dokazano da je najveći broj odustajanja pacijenata $\mathrm{u}$ fazi $\mathrm{C}$ kada oni moraju da shvate šta je bio okidač koji ih je dovedu u situaciju da postanu zavisnici. Oni tada proživljavaju sve iznova, suočavaju se sa jako teškim osećanjima, kako bi pronašli način da oproste sebi. Jako mali broj pacijenata bude sposoban da pređe preko svega ovoga, zaboravljaju uspehe koje su prošli tokom lečenja i kao rešenje za svoje nedaće, ponovo vide jedino drogu. Kako bi ih ubedili da promene mišljenje, u trenutku kada donesu odluku da odustanu od terapije, dakle kada dođu do faze $\mathrm{C}$, psiholozi u ovom eksperimentu, na osnovu ličnog pristanka, pacijente šalju na dve nedelje u sobu sa pacijentom iz faze A, koji prolazi period kriziranja i detoksikacije. Nakon te dve nedelje, pacijenti mogu da napuste lečenje, ali u $80 \%$ slučajeva, lečenje se nastavlja.

\subsection{Zaključak}

Svi navedeni primeri navode na bitna pitanja, ali i daju mnogo odgovora na temu oblikovanja, ambijenta i uopšteno samog pristupa projektovaju jednog ovakvog centra. Treći primer je pravi oblik samoodrživog seoskog gazdinstva gde njegovi stanari održavaju objekat, zemljište i vode brigu o životinjama, a onda ubiraju plodove svog rada.

Ovakav primer organizacije rehabilitacionog centra se pokazao kao veoma uspešan kod pacijenata, jer stvara odgovornost, vraća saopouzdanje, i priprema zavisnika za povratak u stvarne životne tokove van centra. Na osnovu izloženih primera, vidimo da objekti ovog tipa zahtevaju prirodno, izolovano okruženje sa spojem psihičke i fizičke terapije kroz razgovore, rad, rekreaciju umetnost i mnoštvo drugih programa koji bi trebali da se nađu $u$ sklopu kompleksa.

\section{PROJEKTNI ZADATAK}

U okviru istraživanja i predloga rešenja, potrebno je dati jasnu ideju i obrazloženje o nameni objekata i ustanova ovog tipa, i njihovom značaju, za društvo. Nakon toga treba pristupitti procesu projektovanja i osmišljavanja kompleksa, u cilju stvaranja plemenitih prostora koji u potpunosti zadovoljavaju potreba svojih korisnika. I kao poslednja, ali ne najmanje bitna stavka su odabir boja, materijala, rasvetnih tela, kako za eksterijer tako i za enterijer. Ovom zadatku treba posvetiti ogromnu pažnju, jer od odabira primenjenih materijala i boja, određujemo kako će se pacijenti osećati u prostoru u kom borave.

\subsection{Analiza lokacije}

Za lokaciju je odabrana planina Tara, sa akcentom na jezero Zaovine. Kako je to planina poznata kao vazdušna banja, sa dobrom klimom, na oko $881 \mathrm{~m}$ nadmorske visine, udaljena od gradske vreve, urbanih kafića, bez bogatog noćnog života i svega što bi privuklo pažnju zavisnika i vratilo ih na staro, a ujedno bogata florom i faunom, istakla se kao idealna lokacija za formiranje centra za odvikavanje od droge. Tako ušuškano, izdvojeno od prometnih saobraćajnica, gradova, gužve, i stresnih situacija, a opet lako dostupno, sa prelepim predelima, predstavlja pozitivno i stimulativno okruženje, idelano mesto za fizički i psihički oporavak zavisnika od narkotika.

\subsection{Prostorni koncept rehabilitacionog centra}

$\mathrm{U}$ centru pacijenti pored individualnih terapija $\mathrm{i}$ razgovora sa stručnim osobljem imaju i grupne sastanke na kojima prepričavaju svoja iskustva. Predloženi koncept arhitektonske studije rehabilitacionog centra će nastojati da svojom arhitekturom oslika stanje pacijenata kroz sve četiri faze terapije koju prolaze. Da put kojim prolaze prati arhitekturu samog objekta i da njihova osećanja sa kojima se bore postanu vidljiva i opipljiva i na kraju, da je moguć pozitivan ishod lečenja i da je ono što ih čeka nakon terapije neuporedivo sa onim šte se dešavalo $u$ periodu zavisnosti. Iako su prostorno prikazane samo tri faze rehabilitacije, četvrta, D faza nije zapostavljena $\mathrm{i}$ zaboravljena. Kako ona predstavlja period adaptacije na novu sredinu, ona se manifestuje kroz obilazak i rad u štalama, njivama, i održavanju kompleksa. Kako bi organizacija u kompleksu kvalitetno funkcionisala, smeštajni kapacitet ne sme prelaziti četrdeset članova. Svi članovi bi dobijali dnevne zadatke koje bi obavljali. Oni će se stojati od brige o životinjama, što se pokazalo kao korisno kod pobuđivanja humanosti kod pacijenata, i načina da im se vrati osećaj za brigu o drugima.

\subsection{Oblikovanje, materijalizacija, mikroklima}

Prilikom odabira materijalizacije u toku projektovanja kompleksa, poseban pažnja je usmerena ka vrsti, teksturi i boji, jer oni igraju veoma bitnu ulogu u dizajnu stimulativnih prostora što ovaj kompleks svakako teži da 
bude. Za ulaznu frontalnu fasadu i pristupni hodnik koji razdvaja celine $\mathrm{A}$ i $\mathrm{C}$, odabrani su teški materijali $\mathrm{i}$ turobne boje kako bi se poistovetili sa duševnim i telesnim stanjem zavisnika kada stupe u rehabilitacioni centar. To su u prvom redu natur beton i granit ploče (Slike 6-8).
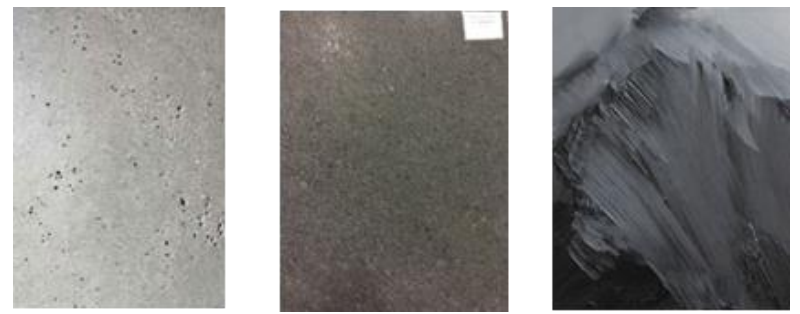

Slike 6-8. Primenjeni materijali u pristupnom holu

Kako pacijent prelazi iz faze $u$ fazu, tonalitet boja, i odabir materijala, postaje topliji, sve vedriji, laksi, i vazdušastiji. Dobija se utisak topline, ušuskanosti, „domaće atmosfere“ sigurnosti, što je u daljim fazama lečenja neophodno. Svetle nijanse odaju utisak topline i domaće atmosfere (Slika 10).
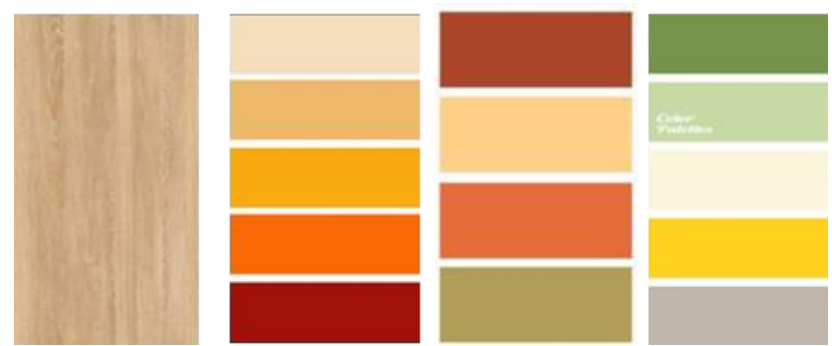

Slika 10. Primenjeni materijali u pristupnom holu

Kako se bliži zvršetak terapije, i pacijenti su sve bliži krajnjem cilju, prostor je sve transparentniji, i otvoreniji ka okolini. To je ujedno i priprema za povratak u redovne društvene tokove. Ono što je najbitnije jeste adekvatno okruženje jedne ovakve ustanove. Velika količina zelenila, parkova, igrališta, bašta. Boravak na otvorenom pojačava socijalizaciju odnosa, podstiče interakciju pacijenata, druženje, zajednički, kreativni rad, rekreaciju.

\section{ZAKLJUČAK}

Tipologija rehabilitacionih centara je ozbijna tema $u$ projektovaju. Tokom vremena, menjali su se pristupi u realizaciji terapije, kao i načini i metode lečenja, pa su se tako menjali $\mathrm{i}$ funkcionalni $\mathrm{i}$ estetski principi pri projektovanju ovakvih objekata. Imajući $u$ vidu nepostojanje adekvatnih ustanova ovog tipa na našim prostorima, kao i loše rezultate onih koje su realizovane, ovaj rad ima za cilj pre svega skretanje pažnje na ovaj ogroman problem, koji je sve zastupljeniji, naročito $\mathrm{u}$ mlađoj populaciji.
Shodno tome, projektovan je objekat koji bi po savremenim istraživanjima dao najbolje rezultate nakon terapije i na najbolji način pomogao zavisnicima. Na osnovu istraženih $\mathrm{i}$ dostupnih podataka o čitavom problemu, smatra se da je ovakav kompleks najbolje pozicionirati daleko od gradova, prometnih saobraćajnica i stresnih situacija, potpuno ga podrediti prirodi. Stvaranje seoskog gazdinstva i njegove identifikacije sa prostorom na kom se nalazi je pokretač u fazi projektovanja ovog rehabilitacionog centra. Ideja tranzicione sobe je bila vodilja pri formiranju koncepta za ovaj rehabilitacioni centar. Na osnovu saznanja o tom projektu, zaključeno je da treba iskoristiti i prostor i njegove korisnike za motivaciju svakog novopridošlog pacijenta. Stvoriti prijatan prostor koji motiviše, pruža utočište i sigurrnost i vraća izgubljeno samopouzdanje i samopoštovanje.

\section{LITERATURA}

[1] S. O'Hara, "Šta su terapijske zajednice", http://www.fundingcaring.co.uk/what-are-therapeuticcommunities.html, Avgust 2010.

[2] P. Nastasić, Terapijska zajednica, predavanje

[3] M. Bulatović, "Djavo u prahu”, Izdrvački fond SPC, Beograd, 2004.

[4] Kristijana F, “Mi deca sa stanice Zoo”, Zagreb, 1995.

[5] Miomir Ristić, "Stimulativni prostori", Arhitektonski fakultet, Beograd, 2010.

[6] S. Trkalj - Ivezić, "Terapijska zajednica, soc. psihijatrija", Zagreb, 2014.

\section{Kratka biografija:}

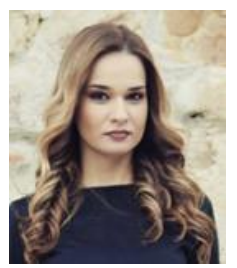

Ksenija Popadić rođena je 04.10.1991. u Šapcu. Osnovne akademske studije na Fakultetu tehničkih nauka iz oblasti Arhitekture i urbanizma završila je 2015. god. Master rad iz oblasti Arhitekture i urbanizmaElementi i sklopovi u arhitektonskom i urbanističkom projektovanju, odbranila je 2018. godine. kontakt: ksenijapop91@ @otmail.com

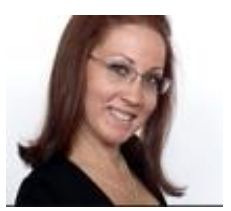

Dr Milena Krklješ rođena je u Novom Sadu 1979. godine. Diplomirala 2002, a magistrilara 2007. godine na Fakultetu tehničkih nauka u Novom Sadu. Doktorirala je 2011. u zvanje vandrednog profesora na Departmanu za arhitekturu i urbanizam izabrana je 2016. god. 